\title{
Improving Hand Hygiene Compliance in Nursing Homes: Protocol for a Cluster Randomized Controlled Trial (HANDSOME Study)
}

Gwen R Teesing ${ }^{1,2}$, MA, MSc; Vicki Erasmus ${ }^{1}$, PhD; Mariska Petrignani ${ }^{3,4}$, MD; Marion P G Koopmans ${ }^{5}$, DVM, $\mathrm{PhD}$; Miranda de Graaf ${ }^{5}, \mathrm{PhD}$; Margreet C Vos ${ }^{6}, \mathrm{MD}, \mathrm{PhD}$; Corné H W Klaassen ${ }^{6}, \mathrm{PhD}$; Annette Verduijn-Leenman ${ }^{7}$, MSc; Jos M G A Schols ${ }^{8}$, MD, PhD; Jan Hendrik Richardus ${ }^{1,2}$, MD, PhD; Helene A C M Voeten ${ }^{1,2}$, MSc, MA, PhD

${ }_{1}^{1}$ Department of Public Health, Erasmus MC, University Medical Center Rotterdam, Rotterdam, Netherlands

${ }^{2}$ Municipal Public Health Service Rotterdam-Rijnmond, Rotterdam, Netherlands

${ }^{3}$ Municipal Public Health Service Haaglanden, Den Haag, Netherlands

${ }^{4}$ Municipal Public Health Service Amsterdam, Amsterdam, Netherlands

${ }^{5}$ Department of Viroscience, Erasmus MC, University Medical Center Rotterdam, Rotterdam, Netherlands

${ }^{6}$ Department of Medical Microbiology and Infectious Diseases, Erasmus MC, University Medical Center Rotterdam, Rotterdam, Netherlands

${ }^{7}$ Pieter van Foreest, Delft, Netherlands

${ }^{8}$ Department of Health Services Research and Department of Family Medicine, Maastricht University, Maastricht, Netherlands

\section{Corresponding Author:}

Gwen R Teesing, MA, MSc

Municipal Public Health Service Rotterdam-Rijnmond

Schiedamsedijk 95

Rotterdam, 3011 EN

Netherlands

Phone: 31612160912

Email: g.teesing@rotterdam.nl

\begin{abstract}
Background: Hand hygiene compliance is considered the most (cost-)effective measure for preventing health care-associated infections. While hand hygiene interventions have frequently been implemented and assessed in hospitals, there is limited knowledge about hand hygiene compliance in other health care settings and which interventions and implementation methods are effective.

Objective: This study aims to evaluate the effect of a multimodal intervention to increase hand hygiene compliance of nurses in nursing homes through a cluster randomized controlled trial (HANDSOME study).

Methods: Nursing homes were randomly allocated to 1 of 3 trial arms: receiving the intervention at a predetermined date, receiving the identical intervention after an infectious disease outbreak, or serving as a control arm. Hand hygiene was evaluated in nursing homes by direct observation at 4 timepoints. We documented compliance with the World Health Organization's 5 moments of hand hygiene, specifically before touching a patient, before a clean/aseptic procedure, after body fluid exposure risk, after touching a patient, and after touching patient surroundings. The primary outcome is hand hygiene compliance of the nurses to the standards of the World Health Organization. The secondary outcome is infectious disease incidence among residents. Infectious disease incidence was documented by a staff member at each nursing home unit. Outcomes will be compared with the presence of norovirus, rhinovirus, and Escherichia coli on surfaces in the nursing homes, as measured using quantitative polymerase chain reaction.
\end{abstract}

Results: The study was funded in September 2015. Data collection started in October 2016 and was completed in October 2017. Data analysis will be completed in 2020 .

Conclusions: HANDSOME studies the effectiveness of a hand hygiene intervention specifically for the nursing home environment. Nurses were taught the World Health Organization's 5 moments of hand hygiene guidelines using the slogan "Room In, Room Out, Before Clean, After Dirty," which was developed for nursing staff to better understand and remember the hygiene guidelines. HANDSOME should contribute to improved hand hygiene practice and a reduction in infectious disease rates and related mortality.

Trial Registration: Netherlands Trial Register (NTR6188) NL6049; https://www.trialregister.nl/trial/6049

International Registered Report Identifier (IRRID)： DERR1-10.2196/17419 
(JMIR Res Protoc 2020;9(5):e17419) doi: 10.2196/17419

\section{KEYWORDS}

hand hygiene; protocol; nurse; nursing home; randomized controlled trial; intervention

\section{Introduction}

Health care-associated infections (HAI) are a significant source of morbidity in nursing home residents. If we include urinary tract infections, we see on average more than one HAI per resident per year in European nursing homes [1]. Not only do residents become ill from HAI but HAI may also affect staff due to their own illness and increased workload, further disrupting care. Hand hygiene $(\mathrm{HH})$ can play a role in an infection prevention strategy.

Most studies focus on hand hygiene compliance (HHC) in hospitals, ignoring other settings with vulnerable populations, such as nursing homes [2]. The few published studies that recorded $\mathrm{HHC}$ in nursing homes according to the World Health Organization (WHO) standards show estimates of $6 \%$ to $27 \%$ $\mathrm{HHC}$ before an intervention [3-7]. There is some evidence that infectious disease rates and mortality rates decrease in nursing homes when HHC increases through $\mathrm{HH}$ interventions [4,8-10]. While most $\mathrm{HH}$ intervention studies document $\mathrm{HHC}$ rates in hospitals, there are a few published studies showing that interventions can significantly influence $\mathrm{HHC}$ in a nursing home $[4,8,11]$. For example, 2 studies in long-term care facilities in Hong Kong showed significant increases in $\mathrm{HHC}$ in intervention arms (27\% to $61 \%, P<.001 ; 22 \%$ to $49 \%, P<.001$; and $26 \%$ to $33 \%, P=.10$ ), no significant changes in control arms after implementing multifaceted $\mathrm{HH}$ interventions involving the provision of hand sanitizer, reminder materials, education, and, in one case, performance feedback $[4,8]$. In Taiwan, nursing assistants showed significantly better HHC (from $9 \%$ to $30 \%$, $P<.001) 3$ months after participating in a 1-hour class and 30 minutes of hands-on training [11].

Due to a paucity of $\mathrm{HH}$ studies in nursing home settings using the WHO hand hygiene standards, we designed a trial to evaluate the impact of an intervention package tailored to the specific context of nursing homes. $\mathrm{HH}$ interventions developed for hospitals are not necessarily appropriate for nursing homes. First, the $5 \mathrm{HH}$ moments of the WHO are difficult to interpret and use in the nursing home setting. The 5 moments of the WHO dictate that $\mathrm{HH}$ should be done before touching a patient, before a clean/aseptic procedure, after body fluid exposure risk, after touching a patient, and after touching patient surroundings. At the same time, a patient's surroundings in a nursing home is a fluid concept. Nursing home residents are generally mobile, sharing communal areas. For example, should touching a resident's walking frame in the living room be considered touching a resident's environment (after which $\mathrm{HH}$ is indicated)? Is a section of a table in a living room a particular "resident's environment" because that resident is sitting there at that moment? Second, interventions should minimally disturb the homelike setting. For example, hanging hand sanitizer dispensers on beds could be perceived as transforming the homelike environment to a medicalized one. Another difference is that nurses in nursing homes generally have less education than nurses who work in hospitals. The intervention should therefore be adapted to their educational level by using simple language and hands-on exercises [12].

The HANDSOME study was developed to evaluate the effectiveness of an intervention to improve HHC in nursing homes. An additional goal of the study is to determine if an intervention is more effective when implemented following an outbreak. In this paper, we describe the study design and protocol details of the HANDSOME study.

\section{Methods}

\section{Overview}

The HANDSOME intervention is based on our experience with developing $\mathrm{HH}$ interventions in hospital and childcare settings. We performed a randomized controlled $\mathrm{HH}$ study in 15 hospitals throughout the Netherlands [13]. Underlying determinants for $\mathrm{HHC}$ were addressed through various means, including making changes to the physical environment (eg, adding dispensers), creating new social norms, and implementing an $\mathrm{HH}$ e-Learning program. While the control and intervention arms did not differ in $\mathrm{HHC}$ at baseline, there was a statistically significant difference in HHC during the follow-up between the control $\operatorname{arm}(24.9 \%$ HHC) and intervention arm (35.4\% HHC) [14]. In childcare settings, we conducted a cluster randomized controlled trial including providing $\mathrm{HH}$ products, providing $\mathrm{HH}$ training to childcare workers, organizing team sessions to promote goal setting, and providing stickers and posters for caregivers and children as cues to action. This led to a statistically significant increase in HHC in the intervention arm, even 6 months after the intervention [15]. Considering the significant increases in $\mathrm{HH}$ in these settings, we adapted these interventions for the current study.

\section{Trial Design}

HANDSOME is a parallel-group, observer-blinded, and observed-blinded cluster randomized controlled trial to increase nurses' HHC. For the purpose of this study, nurses were defined as those who have completed a 3-year or 4-year degree in nursing. The study has 3 study arms: 2 intervention arms and 1 control arm. Nursing homes were randomized to one of the 3 trial arms: fixed intervention, conditional intervention, and control. The nursing homes in the 2 intervention arms received the same intervention, while the control nursing homes did not receive the intervention. The nursing homes in the fixed intervention arm received the intervention at a predetermined date, while the nursing homes in the conditional intervention arm received the same intervention as the fixed intervention arm, but only after an infectious disease outbreak. The conditional intervention arm was conceived with the idea that an outbreak would cause an increased sense of infection risk and urgency, leading towards a better and/or more sustained $\mathrm{HH}$ performance. The control locations were free to implement any other infection prevention intervention, since this is 
"business as usual" and it is unethical to withhold care improvements from residents. Nursing homes were observed several times for HHC, required to complete illness incidence reports, and subjected to microbiological surface sampling.

Background information about the nursing homes was collected through a structured interview. This was followed by a baseline observation in every nursing home unit. Next, nursing homes were randomized into 1 of the 3 study arms. Randomization was at the level of the nursing home rather than the individual nurse or ward, since the intervention was available to an entire nursing home. The aim was to include a minimum of 55 nursing homes: 15 fixed intervention nursing homes, 25 conditional intervention nursing homes, and 15 control nursing homes (see Sample Size Calculations).

A tablet-based app was used to document compliance. Results from background interviews, pilot observations, and the pilot intervention were used to refine the observation app and intervention. Since we were able to determine which types of HH opportunities (submoments) are the most common, these were added to the app to get more insight into HHC. We also used this extra information to address specific $\mathrm{HH}$ issues during the intervention, such as how to handle laundry or use a telephone, tablet, or hand brace. We were also able to specifically incorporate the most common invasive procedures in the intervention lessons. The pilot intervention allowed us to revise the materials so that they were easier to use.

\section{Trial Aim}

We aimed to increase compliance with the WHO's 5 moments of $\mathrm{HH}$ [16], which was measured during repeated observations over a period of 12 months.

\section{Study Setting}

All data were collected in nursing homes in the Netherlands. To capture diversity, these nursing homes are situated throughout the country in areas with differing degrees of urbanization.

\section{Recruitment}

Recruitment of nursing homes began by sending printed flyers with information about the study to large nursing home organizations listed on a website that lists most health care providers in the Netherlands (ZorgkaartNederland). Digital flyers were also sent to health care associations so they could inform their members about the study. In addition to the nursing homes recruited for the study, 3 nursing homes from 3 distinct organizations were recruited as pilot locations to train observers and test the intervention. After the distribution of the flyers, organizations were contacted by phone to discuss willingness, eligibility, and conditions for participation. Interested nursing homes were visited personally to further discuss participation. Enrollment began April 25, 2016. Participants are no longer being recruited.

\section{Eligibility Criteria}

Eligibility criteria were identified to foster homogeneity between nursing home units. First, only publicly funded organizations willing to commit 3 or 4 nursing homes to the study were eligible. By allocating different nursing homes within the same organization to different study arms, we aimed to minimize variation between the study arms. Each nursing home committed a minimum of 2 eligible units. Nursing home wards were considered eligible as a unit if they had 3 or more nurses working between 8:00 am and 2:00 pm on weekdays so that we could observe a minimum of 3 nurses during one observation session. If there were not enough nurses employed during those hours in one ward, multiple wards were combined and considered 1 unit for purpose of this study. If a nursing home could only supply 1 unit, it was coupled with a unit from another nursing home from the same organization. All wards primarily provided somatic or psychogeriatric residential care. Nursing homes were allowed to perform other infection prevention improvements, provided they did not simultaneously participate in other $\mathrm{HH}$ trials.

\section{Allocation}

The randomization process was accomplished through a stepwise procedure after baseline observations. The primary investigator first drew (computer-generated) one nursing home per organization at random for the fixed intervention arm. After this, one nursing home per organization was randomly drawn for the conditional intervention arm. The remaining nursing homes were randomly assigned to the conditional intervention arm or the control arm. This method allowed for random allocation while minimizing the variation between the study arms.

\section{Intervention}

Studies have shown that using multiple strategies that address multiple determinants (eg, a multimodal approach) is the most effective in increasing HHC [17]. Another key determinant for good HHC is repetition [17-19]. These were the cornerstones of our intervention.

For the purpose of the current trial, we scanned literature for determinants that influence $\mathrm{HH}[18,20,21]$, in particular for determinants that we had not considered in our earlier interventions. Additionally, 5 interviews were held at nursing homes for a better understanding of obstacles to HH. Next, intervention mapping principles were used to further recognize applicable determinants, methods, and strategies for the development of this intervention [22] (Table 1). The intervention was further refined after informal discussions with members of more than 20 nursing home organizations during the recruitment period. The intervention continued to be adjusted as an iterative process. 
Table 1. Intervention mapping for HANDSOME: using determinants and methods to develop the strategy for intervention components.

\begin{tabular}{l}
\hline Intervention element \\
\hline Meeting with management \\
Present the average HHC ${ }^{\mathrm{a}}$ in nursing homes. Show there is \\
room for improvement. \\
Talk about costs (time and money) and harm (illness of resi- \\
dents and staff) associated with a methicillin-resistant \\
Staphylococcus aureus or norovirus outbreak. \\
Use a form to structurally discuss necessary facilities and fa- \\
cility changes for efficient HH ${ }^{\mathrm{b}}$ practices. Stress that the orga- \\
nization, not the resident, must provide all HH materials. Help \\
optimize where HH materials are stored and how and when \\
they are replaced. \\
Talk about the Dutch guidelines for personal hygiene and \\
noncompliance policies at other organizations. Talk about risk \\
of infection. Use a form to register a (new) personal hygiene \\
policy for the organization. Make sure that employees have a \\
safe space for personal belongings. Offer solutions for person- \\
nel with rings.
\end{tabular}

Let management know that they can receive a "Good hand hygiene" certification if they achieve a minimum HHC.

Convince management that their presence at Lesson 1 will positively influence $\mathrm{HHC}$ results. Plan lessons and the personal hygiene presentation.

\section{Lesson 1}

A senior nursing home manager introduces the intervention and expresses the importance of $\mathrm{HH}$.

Show an HH video. Present health care-associated infection statistics for nursing homes and explain health risk to self and others. Help employees visualize $\mathrm{HH}$ from the perspective of the resident.

Teach using a presentation. Teach "Room In, Room Out, Before Clean, After Dirty." Teach and discuss HH when handling pills, food, and laundry. Teach when to use hand sanitizer or soap and the proper use of gloves.

Team creates a group HH goal.

Introduce the e-Learning and show the nurse's watch they can earn by completing the e-Learning.

Show posters and ask where they want to see the posters. Hand out small bottles of hand sanitizer for use in the e-Learning,

\section{Presentation of the personal hygiene policy}

A senior nursing home manager presents the personal hygiene policy (no long nails, nail polish, rings, bracelets, watches, braces, or long sleeves). Make consequences known for noncompliance.

\section{Lesson 2}

Make an inventory of barriers to good $\mathrm{HH}$.

Attitude, knowledge

Systems change

Knowledge

Perceived threat, acknowledging importance

Environmental restructuring, rules and regulations, awareness, assistance for organizational change

Seeing importance, rules and regulations, professional standards

Motivation

Capable leadership

Leadership commitment, framing

Create urgency, framing

Knowledge

Self-efficacy, sense of ownership

Facilitate learning, nonfinancial incentives

Nonfinancial incentives, self-efficacy, sense of ownership

Mandate, perceptions of norms, leadership commitment

Think of solutions for barriers.

$\operatorname{Method}(\mathrm{s}) /$ strategy(s)

Reporting

Consciousness raising, persuasive communication, anticipated regret

Organizational diagnosis and feedback/tailoring, systems change, reduce environmental barriers, persuasive communication, participatory problem solving, structural redesign, cue altering/nudging, consciousness raising, goal setting, problem management tool

Systems change, nonfinancial incentives, mandate, anticipated regret, tailoring, organizational diagnosis tool

Nonfinancial incentives, early commitment

Persuasive communication (with management), planning

Persuasive communication, public commitment, introduce systems change

Persuasive communication, consciousness raising, anticipated regret, shifting perspective

Chunking, using imagery, personal feedback

Implementation intentions/goal setting, social influence, team commitment

Structural redesign, beginning of repeated exposure

Cue altering

Punishment, persuasive communication, role models Discussion

Tailoring, organizational diagnosis, planning coping responses, group discussion, structural redesign, systems change

\section{Lesson 3}

Participants "wash" hands with paint and see where they miss. Attitude, knowledge

Participation 


\begin{tabular}{|c|c|c|}
\hline Intervention element & Determinant(s) & Method(s)/strategy(s) \\
\hline Participants learn how to disinfect their hands. & Knowledge, self-efficacy & Guided practice \\
\hline $\begin{array}{l}\text { Participants see that they get paint on hands after glove re- } \\
\text { moval and that the paint represents invisible bacteria/viruses. }\end{array}$ & Knowledge & Anticipated regret, rationalize risk \\
\hline $\begin{array}{l}\text { Remind participants that they can earn a watch by completing } \\
\text { the e-Learning. }\end{array}$ & Non-financial incentives & Persuasive communication \\
\hline \multicolumn{3}{|l|}{ E-Learning } \\
\hline $\begin{array}{l}\text { Show playback squelching excuses not to do HH. Show films } \\
\text { from the perspective of the resident. }\end{array}$ & $\begin{array}{l}\text { Professional behavior } \\
\text { standards, attitude }\end{array}$ & Using imagery, shifting perspective \\
\hline $\begin{array}{l}\text { Explain when to use hand sanitizer or soap. Practice using } \\
\text { hand sanitizer with participants. }\end{array}$ & $\begin{array}{l}\text { Knowledge, skills, self- } \\
\text { efficacy }\end{array}$ & Advance organizers, modelling, guided practice \\
\hline $\begin{array}{l}\text { Use videos with correct and incorrect behavior to teach } \mathrm{HH} \\
\text { moments and common } \mathrm{HH} \text { actions. Teach how to perform } \\
\text { HH when preparing food and pills. }\end{array}$ & Knowledge & Chunking, modelling, active learning \\
\hline $\begin{array}{l}\text { Teach how to work efficiently to avoid unnecessary HH using } \\
\text { videos with correct and incorrect behaviors. }\end{array}$ & $\begin{array}{l}\text { Clinical work process } \\
\text { flow }\end{array}$ & Systems change \\
\hline $\begin{array}{l}\text { Teach the proper use of gloves with still images and videos } \\
\text { with correct and incorrect behaviors. }\end{array}$ & $\begin{array}{l}\text { Perceived norms, knowl- } \\
\text { edge }\end{array}$ & $\begin{array}{l}\text { Active learning, imagery, modelling, persuasive com- } \\
\text { munication }\end{array}$ \\
\hline $\begin{array}{l}\text { Show that } \mathrm{HH} \text { does not inhibit other tasks or social contact } \\
\text { with the resident. }\end{array}$ & Self-efficacy & Modelling \\
\hline Give a quiz after every module. & Knowledge & Reinforcement through testing, feedback, monitoring \\
\hline $\begin{array}{l}\text { Promise a nurse's watch when the e-Learning is completed. } \\
\text { Use dripped learning so that the e-Learning is completed in } \\
\text { small modules over } 14 \text { weeks. Send reminders. }\end{array}$ & $\begin{array}{l}\text { Curiosity, information } \\
\text { system, knowledge, non- } \\
\text { financial incentive }\end{array}$ & Facilitation, anticipated regret, reminders, repetition \\
\hline \multicolumn{3}{|l|}{ Poster } \\
\hline $\begin{array}{l}\text { Multiple copies of a new poster are hung throughout the } \\
\text { nursing home every month. }\end{array}$ & $\begin{array}{l}\text { Social influence, per- } \\
\text { ceived norms }\end{array}$ & Visuals, repeated exposure, cue to action \\
\hline \multicolumn{3}{|l|}{ Photo competition } \\
\hline $\begin{array}{l}\text { Let nursing home employees know they can win a prize for } \\
\text { the best photo of hands. }\end{array}$ & Nonfinancial incentives & Providing cues \\
\hline \multicolumn{3}{|l|}{ Arts and crafts project } \\
\hline $\begin{array}{l}\text { Residents are informed about } \mathrm{HH} \text { and the organization's } \mathrm{HH} \\
\text { goals. }\end{array}$ & Knowledge & Consciousness raising \\
\hline $\begin{array}{l}\text { Residents perform an activity involving hands. Nursing home } \\
\text { displays artwork. }\end{array}$ & Perceived norms & Participation, cues to action \\
\hline
\end{tabular}

${ }^{\mathrm{a}} \mathrm{HHC}$ : hand hygiene compliance.

${ }^{\mathrm{b}} \mathrm{HH}$ : hand hygiene.

The intervention has 4 main components: a meeting with the management, 3 live group lessons, e-Learning, and posters. Additionally, there is a photo competition and an arts and crafts project. All components were published on a website after completion of the intervention [23].

\section{Meeting With Management}

A meeting at the nursing home took place 1-2 months after the baseline compliance measurement. A senior nursing home manager, infection prevention specialist, and facilities manager were asked to attend the meeting. The meeting started with consciousness raising about the cost of a methicillin-resistant Staphylococcus aureus (MRSA) outbreak so the participants would anticipate regret if they did not implement necessary changes. Next, information about the intervention and necessary facilities for $\mathrm{HH}$ were presented. Removing environmental barriers and adding cues to action were discussed, including the strategic placement of hand sanitizer and posters. Tailored system changes were advised to encourage better $\mathrm{HH}$, such as how to hygienically dispose of dirty laundry.

The Dutch guidelines for (hand-related) personal hygiene dictate that staff members providing care do not wear rings, nail polish, artificial nails, long nails, bracelets, watches, a brace, or long sleeves [24]. Policy changes for personal hygiene noncompliance were discussed, including disciplinary consequences. Management was also asked to give a personal hygiene presentation between the first and second lesson. Although personal hygiene is broader than hand-related personal hygiene, we stressed the need to address hand-related personal hygiene. 
Nursing homes were also promised a nonfinancial incentive. If they had a higher than average $\mathrm{HHC}$, they would receive a certificate of good $\mathrm{HH}$. At the end of the meeting, an intervention implementation schedule was discussed. While the compliance measurements were only completed at certain wards, all nurses and nurses' aides from the entire nursing home were welcome to participate in the intervention.

\section{Lessons}

A member of the study team provided 3 lessons lasting a half hour each. The lessons were generally given multiple times on one day to a maximum of 18 participants per session.

The first lesson began with an introduction by a senior nursing home manager, showing leadership commitment to systems change. The first goal of the lesson was to create awareness about the necessity of HH. Still images, video, and a persuasive live presentation promoted consciousness raising and anticipated regret. The second goal was to teach the participants when they needed to perform $\mathrm{HH}$. They were taught using a novel description of the $5 \mathrm{HH}$ moments of the WHO [25], namely "Room In, Room Out, Before Clean, After Dirty" ("Kamer in, Kamer uit, Voor schoon, Na vies"). "Room In" corresponds to the WHO Moment 1 (before touching a patient). "Room Out" corresponds to WHO Moment 4 (after touching a patient) and Moment 5 (after touching patient surroundings). "Before Clean" corresponds to WHO Moment 2 (before a clean/aseptic procedure), and "After Dirty" corresponds to WHO Moment 3 (after body fluid exposure risk). This method comprises the same HH moments as the WHO standard, is more adapted to the nursing home setting, is easier to remember (one slogan), and is easier to visualize.

After explanation of the $\mathrm{HH}$ moments and reiteration that the participants are now expected to follow the rules for $\mathrm{HH}$, the participants had time to ask questions. The next step was to ask the participants to pick a $\mathrm{HH}$ goal that would receive extra attention. This group goal was a moment that they thought was attainable and immediately implementable. The main reasons for creating a goal were to reflect upon what was just learned, create a sense of ownership, and create team commitment. All goals mentioned during the day's session were printed on a small poster and hung in the nurses' office to act as a reminder.

A larger, colorful poster was presented. Participants were told that different posters would come every month and asked where they would like the posters to hang so that they felt ownership of the project.

To encourage e-Learning participation, participants received a nurse's watch (which you can pin on your clothing) after completion of the e-Learning. They also left the meeting with an immediate reward, since they left with a small bottle of hand sanitizer to be used during the e-Learning. This was done to create a positive association with $\mathrm{HH}$. After Lesson 1, the management-level contact(s) were informed in person and by mail of any pertinent staff comments so that they could consider making system or facility changes.

Between Lesson 1 and Lesson 2, a senior nursing home manager presented the newest rules for personal hygiene to the nurses and nurses' aides. Materials were made available to assist the manager with the presentation, including a picture of an agar with bacterial growth caused by a ring and a poster displaying personal hygiene rules. Nurses and nurses' aides were informed of their organization's disciplinary consequences if they did not adhere to the personal hygiene rules.

Lesson 2 lasted 30 minutes and was usually combined with Lesson 3 to create one lesson of 50 minutes. The main goal of the second lesson was to remove the barriers that nurses experience when trying to perform $\mathrm{HH}$. Each participant was given a sheet with 28 stickers representing 13 different barriers. There were 2 blank stickers, allowing participants to write down any additional barriers. The stickers represented 4 themes, namely facilities, forgetting, choosing not to do $\mathrm{HH}$, and the telephone. The barriers were identified through literature, interviews, and observations.

Sheets of paper were hung on the walls, one sheet for each of the 4 elements of the slogan (Room In, Room Out, Before Clean, After Dirty). Participants were asked to place one sticker on each piece of paper representing the main reason that he or she did not perform $\mathrm{HH}$ at that moment. This system facilitates an organizational diagnosis of $\mathrm{HH}$ impediments. Once the stickers were placed, the most prevalent barriers were discussed. Group discussions resolved barriers by designing new coping strategies, cues to action, and environmental changes. The barrier analysis with solutions was in turn discussed with the nursing home manager so that any necessary system or facility changes could take place.

During Lesson 3, participants learned the correct execution of $\mathrm{HH}$ through active participation. Using gloves and paint, participants saw which parts of their hands they missed when washing them incorrectly and that fluids, bacteria, and viruses can get on hands during glove removal. They also learned the correct HH procedure. Although the WHO promotes a 6-step method [25], wrist rubbing was added since this area can easily be contaminated when removing gloves. After the third lesson, management was informed of any participant feedback that could influence HHC.

\section{E-Learning}

The e-Learning served two purposes: It allowed nurses and nurses' aides who were unable to attend the live lessons to gain $\mathrm{HH}$ knowledge, and it provided reinforcement of these lessons. The e-Learning consisted of an introduction and 7 lessons. The themes of the lessons were the resident's perspective, how to wash and disinfect your hands, when to execute $\mathrm{HH}, \mathrm{HH}$ in combination with sterile activities, time-saving work habits, glove use, and social aspects of $\mathrm{HH}$. Videos modelled knowledge, guided practice, and promoted active learning by encouraging participants to scrutinize videos.

After viewing the introduction, the participant was invited every other week to complete the next lesson. This method provided participants with regular reminders to perform $\mathrm{HH}$. Each lesson lasted 5-10 minutes and ended with a quiz to reinforce the message. After completing the entire e-Learning, the participant received a certificate and a nurse's watch. 


\section{Posters, Photo Competition, and an Arts and Crafts Project}

To reinforce the message, 3 supplementary components were developed, namely posters, a photo competition, and an arts and crafts project. The posters acted as reminders and included large pictures of hands and the text: "Did you remember to wash your hands?" (Vergeet je niet je handen te wassen?). The posters were designed to be visually appealing with a cheery image so that they could be placed in living areas. New posters were distributed monthly over a 10-month period so that the message would repeatedly capture attention. Of these posters, 5 came from the photo competition and the arts and crafts project.

Participants were invited to submit a photo for the photo competition. The idea behind this activity was to get nurses to think about $\mathrm{HH}$ in diverse situations, including outside the workplace. The photo submission needed to contain pictures of hands. The winners of the 3 best photos received a gift certificate. Their photos were used for 3 of the monthly posters.

Additionally, nursing homes received a package of information containing instructions on implementing a hand-related arts and crafts project with the residents. This activity had 3 goals: to create a training moment for the residents to learn when to perform $\mathrm{HH}$, to inform residents that the staff is paying more attention to $\mathrm{HH}$, and to again remind staff to perform $\mathrm{HH}$. The
2 most appealing pieces of art were turned into 2 of the monthly posters.

\section{Strategies to Improve and Monitor Adherence to Protocols}

While the researcher used persuasive communication to convince nursing home management to allow the entire nursing staff to participate in all 3 lessons, we assumed that not everyone would attend. Intervention adherence was documented. Attendance at the HH lessons and e-Learning lessons was recorded. Additionally, attendees were asked in the process evaluation if they received information about personal hygiene policy and if they saw $\mathrm{HH}$ posters hanging in the nursing home.

\section{Outcomes}

\section{Primary Outcome Measure}

HHC is the primary outcome measure. HHC is defined as the number of times that $\mathrm{HH}$ is performed at an $\mathrm{HH}$ opportunity (according to the WHO's 5 moments of $\mathrm{HH}$ ), divided by the total number of times that it should be performed, expressed as a percentage. We only documented $\mathrm{HH}$ as compliant if hand sanitizer or soap, water, and a paper towel were used. Compliance was measured through live observations, still considered the gold standard, even though there is a risk of observer bias and the Hawthorne effect $[26,27]$. There were 4 registered timepoints (Table 2). 
Table 2. Timeline of the study.

\begin{tabular}{|c|c|c|c|c|c|c|c|c|c|c|}
\hline \multirow[b]{3}{*}{ Timepoint } & \multicolumn{10}{|l|}{ Study period } \\
\hline & \multirow{2}{*}{$\begin{array}{l}\text { Recruitment } \\
\text { Mar-Sep } \\
2016\end{array}$} & \multirow{2}{*}{$\begin{array}{l}\text { Baseline } \\
\text { Oct } 2016\end{array}$} & \multirow{2}{*}{$\begin{array}{l}\text { Randomization } \\
\text { Nov } 2016\end{array}$} & \multicolumn{6}{|c|}{ Post-allocation } & \multirow{2}{*}{$\begin{array}{l}\text { Close-out } \\
\text { Nov-Dec } \\
2017\end{array}$} \\
\hline & & & & $\begin{array}{l}\text { Dec } \\
2016\end{array}$ & $\begin{array}{l}\text { Jan } \\
2017\end{array}$ & $\begin{array}{l}\mathrm{Feb} \\
2017\end{array}$ & $\begin{array}{l}\text { Mar-Apr } \\
2017\end{array}$ & $\begin{array}{l}\text { May } \\
2017\end{array}$ & $\begin{array}{l}\text { Oct } \\
2017\end{array}$ & \\
\hline \multicolumn{11}{|l|}{ Recruitment } \\
\hline Eligibility screening & $\mathrm{X}$ & $-^{\mathrm{a}}$ & - & - & - & - & - & - & - & - \\
\hline Signed commitment & $\mathrm{X}$ & - & - & - & - & - & - & - & - & - \\
\hline Randomization & - & - & $\mathrm{X}$ & - & - & - & - & - & - & - \\
\hline \multicolumn{11}{|c|}{ Intervention (fixed intervention arm) ${ }^{b}$} \\
\hline Meeting with management & - & - & - & $\mathrm{X}$ & - & - & - & - & - & - \\
\hline Lesson 1 & - & - & - & - & $\mathrm{X}$ & - & - & - & - & - \\
\hline Lessons $2 \& 3$ & - & - & - & - & - & - & $\mathrm{X}$ & - & - & - \\
\hline E-Learning ${ }^{\mathrm{c}}$ & - & - & - & - & $\mathrm{X}$ & $\mathrm{X}$ & $\mathrm{X}$ & $\mathrm{X}$ & $\mathrm{X}$ & - \\
\hline Posters $^{c}$ & - & - & - & - & $\mathrm{X}$ & $\mathrm{X}$ & $\mathrm{X}$ & $\mathrm{X}$ & $\mathrm{X}$ & - \\
\hline \multicolumn{11}{|l|}{ Assessments } \\
\hline Structured interview & $\mathrm{X}$ & - & - & - & - & - & - & - & - & - \\
\hline Compliance observations & - & $\mathrm{X}$ & - & - & - & $X$ & - & $X$ & $X$ & - \\
\hline Illness registry $^{c}$ & - & $\mathrm{X}$ & $\mathrm{X}$ & $\mathrm{X}$ & $\mathrm{X}$ & $\mathrm{X}$ & $\mathrm{X}$ & $\mathrm{X}$ & $\mathrm{X}$ & - \\
\hline Microbiology samples & - & $\mathrm{X}$ & - & - & - & $X$ & - & $\mathrm{X}$ & - & - \\
\hline Process evaluation & - & - & - & - & - & - & - & - & - & $\mathrm{X}$ \\
\hline Close-out questionnaire & - & - & - & - & - & - & - & - & - & $\mathrm{X}$ \\
\hline
\end{tabular}

${ }^{\mathrm{a}}$ Not applicable.

${ }^{b}$ For the conditional intervention arm, the intervention timeline was dependent upon the month an outbreak occurred.

${ }^{\mathrm{c}}$ Continuous intervention exposure or measurement.

\section{Secondary Outcome Measure}

The incidence of gastroenteritis, influenza, assumed pneumonia, MRSA, and urinary tract infections in the nursing home residents is the secondary outcome measure. Nursing home staff recorded these infectious diseases on a weekly basis, along with infectious disease outbreaks. The McGeer criteria were used to define the infectious diseases [28].

\section{Additional Outcome Measures}

Additional outcome measures included the presence of norovirus, rhinovirus, and Escherichia coli on 3 types of surfaces in the nursing home. Norovirus is a common viral gastrointestinal pathogen, rhinovirus is a common respiratory pathogen, and $E$. coli is a common bacterial indicator of fecal contamination of the physical environment. To measure the presence of these pathogens, microbiology samples were taken with wipes and sent to the laboratory for analysis. Samples were taken during the first 3 timepoints for the primary outcome.

Hand-related personal hygiene compliance was also documented as an additional outcome measure. This was measured according to Dutch guidelines [24]. A nurse was considered compliant if he or she did not have long nails, acrylic nails, or polished nails and did not wear a ring, bracelet, wristwatch, brace, or long sleeves. Personal hygiene was noted for every nurse who was observed for HHC. Compliance is defined by the percentage of personal hygiene-compliant nurses, divided by the total number of nurses observed. Hand-related personal hygiene compliance was documented at the same timepoints as the primary outcome measure.

\section{Timeline}

The recruitment period lasted from March through September 2016 (Table 2). The trial began with baseline measurements of $\mathrm{HH}$, personal hygiene, and environmental sampling in October 2016 (baseline). At this point, nursing homes began submitting a weekly disease incidence report of the illnesses mentioned earlier. After the baseline measurements, nursing homes were allocated to 1 of the 3 study arms. For the fixed intervention nursing homes, this was followed by a meeting with management, the first lesson, presentation of the e-Learning, start of monthly posters, and announcement of the photo competition. After the first lesson, the first follow-up observations occurred at the fixed intervention and control nursing homes 3 months after baseline. This was followed by the second and third $\mathrm{HH}$ lessons and the dissemination of information about the arts and crafts project at the fixed intervention nursing homes. 6 months after baseline, both the fixed intervention and control nursing homes were observed 
again. The last observation occurred at the fixed intervention and control nursing homes 12 months after baseline.

After randomization, individual conditional intervention nursing homes followed the same schedule as the fixed intervention nursing homes, but only after an outbreak occurred. Preliminary analyses of the outcome measures were performed after every round of observations. All data were collected by December 2017. This study will be completed in 2020 .

\section{Sample Size Calculation}

The $\mathrm{HH}$ intervention was expected to increase $\mathrm{HH}$ compliance from $35 \%$ pre-intervention to $50 \%$ post-intervention. The sample size was calculated based on $80 \%$ power with a two-sided $\alpha$ of .05 , taking into account the clustering of observations within nursing homes and assuming a heterogeneity between nursing homes of 0.4. It was determined that a sample size of 45 nursing homes would be sufficient, with 15 nursing homes participating in each arm. Since we could not assume that all nursing homes in the conditional intervention arm would have an outbreak during the study period, the goal was to have a minimum of 25 nursing homes in this arm.

We aimed to evaluate 2 units at each nursing home and to observe 3 nurses in each unit for a maximum of 2 hours each. This equates to 12 hours of observation per nursing home per observation round, in which we expected to observe $75 \mathrm{HH}$ opportunities, equally divided over the 5 moments of the WHO. We therefore expected approximately 1125 opportunities per arm per observation round.

\section{Blinding}

Blinding the researcher to the intervention arm was not possible in this trial because the researcher also taught the lessons. The nurses were blinded by giving distinct names to the lessons (The New Way of Working) and the observations (HANDSOME), so that they appeared to be different projects. Furthermore, nurses were told that the observers were registering the frequency of health care activities. $\mathrm{HH}$ observers were not informed which nursing homes were receiving the intervention, although they may have noticed $\mathrm{HH}$ posters from the intervention while observing.

\section{Data Collection Instruments}

Before the first observation, nursing home unit managers were interviewed in person or over the telephone. A baseline questionnaire was used to gain more insight into the background characteristics of each individual unit, such as the number of employees, brand of $\mathrm{HH}$ products, and type of care provided by the unit.

We designed a tablet-based observation app to measure $\mathrm{HH}$ and hand-related personal hygiene. The registration events were based on the 5 moments of $\mathrm{HH}$, as determined by the WHO and Dutch guidelines for personal hygiene [16,24]. Hand-related personal hygiene was recorded once for every observed nurse per observation day.

When documenting $\mathrm{HH}$, a distinction was made between the use of hand sanitizer or combination of water, soap, and paper towel. If neither method was used at an opportunity or if the water-soap-paper towel combination was missing one element, then the HH opportunity was considered "missed." To be considered compliant, $\mathrm{HH}$ needed to happen in the same room in which the action occurred. The only exceptions to this rule were if a nurse brought a resident to another room, a nurse carried something soiled, or no door needed to be opened before leaving the room. In these cases, $\mathrm{HH}$ should have taken place at the end of the action.

Compliance to the 5 moments of the WHO was broken down into submoments, giving more insight into the frequency of and compliance at submoments (Table 3). Three additional activities that potentially facilitate pathogen transmission were registered separately, namely the preparation and serving of food and medication, taking gloves to use for non-resident related activities, and social contact. HHC related to food and medication activities was documented since this could be considered a clean procedure (Moment 2). HH before taking gloves for non-resident related activities was noted because taking gloves without first performing $\mathrm{HH}$ may contaminate other gloves from the same box [29]. According to the WHO guideline for long-term health care, $\mathrm{HH}$ is not required during social contact, even though it does involve hand contact and thus potentially facilitates pathogen transmission [16]. We therefore recorded the number of times that this occurred. We defined social contact as patting the shoulder/knee, shaking hands, patting a hand, and hugging. 
Table 3. Moments and submoments for hand hygiene compliance documentation.

\begin{tabular}{|c|c|}
\hline Moment & Submoment \\
\hline $\begin{array}{l}\text { Moment } 1 \\
\text { (before touching a patient) }\end{array}$ & $\begin{array}{l}\text { Washing or providing perineal care in own room, providing perineal care at the toilet, other care, } \\
\text { and after the use of a mobile phone, tablet, or computer during resident contact (during Moment } 1 \\
\text { activities) }\end{array}$ \\
\hline $\begin{array}{l}\text { Moment } 2 \\
\text { (before clean/aseptic procedure) }\end{array}$ & $\begin{array}{l}\text { Catheter care, wound care, injection, feeding tube care, colostomy care, pain pump care, eye drops, } \\
\text { tracheostomy tube care, mucous suction, other invasive care, and after the use of a mobile phone, } \\
\text { tablet, or computer during resident contact (during Moment } 2 \text { activities) }\end{array}$ \\
\hline $\begin{array}{l}\text { Moment } 3 \\
\text { (after body fluid exposure risk) }\end{array}$ & $\begin{array}{l}\text { Invasive care, removing bedding, washing/cleaning the resident in own room, helping resident at } \\
\text { the toilet, other (body fluid of a resident), own body fluid, helping animals, and before the use of a } \\
\text { mobile phone, tablet, or computer during resident contact (during Moment } 3 \text { activities) }\end{array}$ \\
\hline $\begin{array}{l}\text { Moment } 4 \\
\text { (after touching a patient) }\end{array}$ & $\begin{array}{l}\text { Resident care and before the use of a mobile phone, tablet, or computer during resident contact } \\
\text { (during Moment } 4 \text { activities) }\end{array}$ \\
\hline $\begin{array}{l}\text { Moment } 5 \\
\text { (after touching a patient's surroundings) }\end{array}$ & No submoments \\
\hline \multicolumn{2}{|l|}{$\begin{array}{l}\text { Additional potential moments for pathogen } \\
\text { transmission }\end{array}$} \\
\hline Before using gloves (not patient-related) & No submoments \\
\hline Before food and pills & $\begin{array}{l}\text { Preparing or administering medicine, preparing food, serving food, helping with eating, and washing } \\
\text { the resident's hands before eating }\end{array}$ \\
\hline Social contact & Pat on the shoulder, shaking hands, touching a hand, and hugging \\
\hline
\end{tabular}

Once the observations were finished with one nurse, the observer reset the app for the observations with the next nurse. Personal hygiene compliance was only registered one time per nurse.

The residents' infectious disease occurrence was recorded by staff. Each unit received a notebook in which a designated person (nurse, team leader, or geriatrician) recorded the weekly incidence of gastroenteritis, influenza, assumed pneumonia, MRSA, urinary tract infections, and an outbreak. The nursing home was free to decide who was responsible for the reporting. We only collected anonymized patient data. Definitions of the illnesses were given in the notebook to promote homogeneity in reporting. Weekly reports were sent to the researcher via email or WhatsApp.

Microbiology samples were collected at baseline, 3 months after baseline, and 6 months after baseline (Table 2). Samples were taken from a communal table, a communal toilet, and the computer mouse and keyboard. The qualitative molecular detection technique quantitative polymerase chain reaction was used to detect viral indicator organisms and $E$. coli. The wipes used in this process do not supply quantitative results, but they make it possible to cover a larger surface area than with swabs, enhancing the sensitivity.

A process evaluation occurred after the intervention. Every nurse who attended at least one live lesson or started the e-Learning received an email with a link to a process evaluation questionnaire. They were asked questions to measure fidelity at the unit and their opinion about different aspects of the intervention.

After the intervention was completed, a senior nursing home manager participated in a close-out questionnaire to assess system changes or infection prevention programs that may have affected HHC during the study period.

\section{Measuring Compliance: Training and Planning}

Independent observers were trained to observe HHC using an adapted training method from an HHC study in Dutch hospitals [30]. Observers were primarily nurses and doctors in training. These observers were trained over a period of 2-3 days using videos, case studies, and live observations at 2 nursing homes. The training ended with an examination using videos from Hand Hygiene Australia [31]. The observers also received training in collecting microbiological samples.

Observers documented nurses' HHC at the nursing home from 8:00 am to $2: 00 \mathrm{pm}$. The objective was to observe a minimum of 3 nurses, each for a maximum of 2 hours.

\section{Promoting Participant Retention}

If a nursing home considered stopping the intervention, it was encouraged to continue the program through persuasive communication. If the nursing home refused to follow the protocol, the researcher had the option to withdraw the participant from the program. If the nursing home dropped out of the intervention, management was still asked to answer questions in the close-out questionnaire.

\section{Data Management and Dissemination}

Data were collected in different ways. Background information about the nursing homes and information from the close-out questionnaire were collected during interviews and from forms sent from the nursing homes. This information was entered in an Excel (Microsoft Corp, Redmond, WA) document. Weekly infectious disease incidence reports were similarly entered in an Excel document by a dedicated staff member. All compliance data were entered in an app and downloaded into Excel documents. Compliance data will be cleaned in SPSS version 25 (IBM Corp, Armonk, NY). The results of the microbiology samples were entered in an Excel document. Information from 
the process evaluation was gathered with an online survey and downloaded into SPSS. HHC and protocol adherence results were disseminated to participating nursing homes in personalized reports. The results of the study will be made available to the wider community in scientific publications. Data will be managed and archived according to the Quality Manual of the Department of Public Health, Erasmus MC,
University Medical Center Rotterdam. Researchers may request access to the data from the chair of the Department of Public Health, Erasmus MC, University Medical Center Rotterdam.

\section{Statistical Methods}

The various outcomes of the trial (primary, secondary, and additional) will be analyzed separately according to the specific research hypotheses (Table 4).

Table 4. Statistical methods

\begin{tabular}{|c|c|c|c|}
\hline Outcome & Hypothesis & Outcome measure & Methods of analysis \\
\hline Primary: hand hygiene & $\begin{array}{l}\text { Improvement is higher in the intervention } \\
\text { arms than the control arm. }\end{array}$ & Hand hygiene compliance (binary) & Multilevel logistic regression \\
\hline $\begin{array}{l}\text { Secondary: infectious disease } \\
\text { incidence }\end{array}$ & $\begin{array}{l}\text { There will be a lower disease incidence in the } \\
\text { intervention arms than in the control arm. }\end{array}$ & Infectious disease incidence (binary) & Multilevel logistic regression \\
\hline $\begin{array}{l}\text { Additional: presence of } \\
\text { norovirus, rhinovirus, and } E s \text { - } \\
\text { cherichia coli }\end{array}$ & $\begin{array}{l}\text { There will be a lower detection rate of mi- } \\
\text { croorganisms on surfaces in the intervention } \\
\text { arms than in the control arm. }\end{array}$ & $\begin{array}{l}\text { Proportion of samples positive for } \\
\text { norovirus (genogroups I and II), rhi- } \\
\text { novirus (continuous), and Escherichia } \\
\text { coli }\end{array}$ & Multilevel loglinear regression \\
\hline Additional: personal hygiene & $\begin{array}{l}\text { Improvement is higher in the intervention } \\
\text { arms than in the control arm. }\end{array}$ & Personal hygiene compliance (binary) & Multilevel logistic regression \\
\hline
\end{tabular}

\section{Ethics Approval and Consent to Participate}

Ethical approval for the study was waived by the Medical Ethics Review Committee of the Erasmus MC (no.58158). Any significant changes to the study protocol were communicated to the Medical Ethics Review Committee. All changes were communicated to the participants, steering committee, and study sponsor. Consent to participate is not relevant in this study, since we did not collect any patient information. No identifying information about the nurses was collected. All collected data will be anonymized before publication to protect the privacy of the nursing home and nursing home staff. Data sets will be anonymized according to our quality manual and data management plan.

\section{Results}

The study was funded in September 2015. Medical ethical approval was waived in August 2016. Data collection started in October 2016 and was completed in October 2017. In total, 124 nursing home units were recruited in 62 nursing homes. Of these, 116 units were allocated: 36 to the fixed intervention arm, 50 to the conditional intervention arm, and 30 to the control arm. Data analysis is ongoing, and the first results are expected to be published in 2020 .

\section{Discussion}

The HANDSOME study was created to increase HHC in nursing homes. We took this opportunity to not only look at HHC but also to investigate a secondary outcome of the incidence of gastroenteritis, influenza, assumed pneumonia, MRSA, and urinary tract infections in the nursing home residents. The presence of norovirus, rhinovirus, or E. coli on nursing home surfaces was also documented, creating the opportunity to triangulate with $\mathrm{HHC}$ and infectious disease incidence. We also documented hand-related personal hygiene compliance.
The HANDSOME intervention was developed specifically for the nursing home setting. It used a blended learning model to reach as many nurses as possible. HANDSOME reframes the WHO's HH moments so that they are understandable and easily recalled in a nursing home setting. We created the slogan "Room In, Room Out, Before Clean, After Dirty," which incorporates the WHO framework for HH. It specifically takes into account that most health care actions occur in the residents' bedrooms, social contact is excluded from the $\mathrm{HH}$ rules in nursing homes, and it is only feasible to consider the resident's room (or that portion of the room that belongs to him or her) as the resident's surroundings.

"Room In, Room Out" is a concept that has been used before in HH policies, mostly with the terms "Wash In, Wash Out" $[32,33]$. The "Wash In, Wash Out" method is problematic for various reasons. It inherently neglects $\mathrm{HH}$ before an aseptic procedure and after contact with bodily fluids. Additionally, as demonstrated by Sunkesula et al [34], the health care worker would often be expected to do unnecessary $\mathrm{HH}$ when using the "Wash In, Wash Out" method since health care workers often do not touch patients in the patient's room. Furthermore, "Wash In, Wash Out" inherently emphasizes hand washing and ignores the benefits of using hand sanitizer. We address these problems by using the terms "Room In, Room Out, Before Clean, After Dirty" and teaching participants in the lessons and e-Learning that they do not need to perform $\mathrm{HH}$ in a resident's room if they do not touch the resident or the resident's surroundings and they can omit "Room In" if they only touch the resident's surroundings without touching the resident.

Our observational method should also give more insight into HHC moments. Our study is one of the few that looks specifically at the separate moments and submoments of the 5 WHO moments. This way, we can gain better insight into which health care actions occur most frequently in nursing homes and which moments need the most attention to attain a higher HHC and less illness. We also expect to gain more insight into barriers 
for each HH moment. During the second lesson, participants were asked to specify barriers experienced during the different HH moments.

This study should add to the body of evidence that HHC is suboptimal in nursing homes and can be significantly improved through an intervention. We also expect to gain insight in personal hygiene compliance in nursing homes. Another strength of this study is that it created an aggregate register of residents' infections. Although there are some data about HAIs in nursing homes, most nursing homes only register illness in individual dossiers [1]. This study collected data about infection incidence using the same definitions as the National Institute for Public Health and the Environment in the Netherlands so that the data can be compared [35]. This could add more insight and help form the agenda to avoid unnecessary illness. We believe that this is also one of the first studies to systematically sample nursing home surfaces for various viruses and bacteria in order to study the potential added value as an alternative method to monitor HHC.

Another novel aspect of our intervention is that we may discover if an intervention is more successful at a random point in time or after an infectious disease outbreak. We should create more insight into when $\mathrm{HH}$ interventions should be implemented.

This study also has limitations. Since we used the gold standard of measuring $\mathrm{HHC}$, observers directly observed nurses giving care. This may have caused Hawthorne or observer bias. A second limitation is that nursing homes were not required to send every nurse to the lessons, conceivably causing a significant variation in compliance to the protocol. Another limitation could be that observers were able to guess which nursing homes received the intervention, since these nursing homes had $\mathrm{HH}$ posters from the intervention hanging on the walls, which may unconsciously have influenced their observations. Last, we only observed $\mathrm{HH}$ at organizations with at least 3 nursing homes. This study therefore does not necessarily reflect $\mathrm{HHC}$ at smaller organizations.

Considering that there are few studies that have rigorously investigated the WHO's recommendations for $\mathrm{HH}$, HANDSOME will provide needed insight into $\mathrm{HH}$ in nursing homes. The results from this study could help in creating more refined and successful $\mathrm{HH}$ interventions in the future. Future interventions can focus on the moments that are more often missed.

\section{Acknowledgments}

We would like to thank Caspar Looman for the original statistical analysis for sample size calculation and Jennifer Bloem for her assistance in this project. This work is supported by the Netherlands Organization for Health Research and Development (ZonMw) [grant number NL50-53000-98-151]. Essity Hygiene Products AB supplied non-monetary assistance (small bottles of hand sanitizer). ZonMw and Essity have no role in or authority over the design, collection, management, analysis, interpretation, and publication of data or in writing the manuscript.

\section{Conflicts of Interest}

None declared.

\section{References}

1. Latour K, Kinross P, Moro M, Fitzpatrick F, Ricchizzi E, Dillane T. Point prevalence survey of healthcare-associated infections and antimicrobial use in European long-term care facilities, April-May 2013.: European Centre for Disease Prevention and Control; 2014. URL: https://ecdc.europa.eu/sites/portal/files/media/en/publications/Publications/ healthcare-associated-infections-point-prevalence-survey-long-term-care-facilities-2013.pdf [accessed 2019-06-18]

2. Gould DJ, Moralejo D, Drey N, Chudleigh JH, Taljaard M. Interventions to improve hand hygiene compliance in patient care. Cochrane Database Syst Rev 2017 Sep 01;9:CD005186 [FREE Full text] [doi: 10.1002/14651858.CD005186.pub4] [Medline: 28862335]

3. Chuang VW, Tsang IH, Keung JP, Leung JY, Yuk JM, Wong DK, et al. Infection control intervention on meticillin resistant transmission in residential care homes for the elderly. J Infect Prev 2015 Mar;16(2):58-66 [FREE Full text] [doi:

10.1177/1757177414556007] [Medline: 28989403]

4. Ho M, Seto W, Wong L, Wong T. Effectiveness of multifaceted hand hygiene interventions in long-term care facilities in Hong Kong: a cluster-randomized controlled trial. Infect Control Hosp Epidemiol 2012 Aug;33(8):761-767. [doi: 10.1086/666740] [Medline: 22759542]

5. Liu W, Liang S, Wu SV, Chuang Y. Hand hygiene compliance among the nursing staff in freestanding nursing homes in Taiwan: a preliminary study. Int J Nurs Pract 2014 Feb;20(1):46-52. [doi: 10.1111/ijn.12120] [Medline: 24580975]

6. Pan A, Domenighini F, Signorini L, Assini R, Catenazzi P, Lorenzotti S, et al. Adherence to hand hygiene in an Italian long-term care facility. Am J Infect Control 2008 Sep;36(7):495-497. [doi: 10.1016/j.ajic.2007.10.017] [Medline: 18786454]

7. Smith A, Carusone SC, Loeb M. Hand hygiene practices of health care workers in long-term care facilities. Am J Infect Control 2008 Sep;36(7):492-494. [doi: 10.1016/j.ajic.2007.11.003] [Medline: 18786453]

8. Yeung WK, Tam WSW, Wong TW. Clustered randomized controlled trial of a hand hygiene intervention involving pocket-sized containers of alcohol-based hand rub for the control of infections in long-term care facilities. Infect Control Hosp Epidemiol 2011 Jan;32(1):67-76. [doi: 10.1086/657636] [Medline: 21087125] 
9. Temime L, Cohen N, Ait-Bouziad K, Denormandie P, Dab W, Hocine MN. Impact of a multicomponent hand hygiene-related intervention on the infectious risk in nursing homes: A cluster randomized trial. Am J Infect Control 2018 Feb;46(2):173-179. [doi: 10.1016/j.ajic.2017.08.030] [Medline: 28987524]

10. Hocine MN, Temime L. Impact of hand hygiene on the infectious risk in nursing home residents: A systematic review. Am J Infect Control 2015 Sep 01;43(9):e47-e52. [doi: 10.1016/j.ajic.2015.05.043] [Medline: 26184767]

11. Huang $\mathrm{T}, \mathrm{Wu} \mathrm{S}$. Evaluation of a training programme on knowledge and compliance of nurse assistants' hand hygiene in nursing homes. J Hosp Infect 2008 Feb;68(2):164-170. [doi: 10.1016/j.jhin.2007.11.020] [Medline: 18226418]

12. Prins M, Heijkants C, Willemse B. Trends in de verpleeghuiszorg voor mensen met dementie: Monitor Woonvormen Dementie 2008-2017.: Trimbos-instituut; 2018. URL: https://www.trimbos.nl/docs/cf7c0126-5c37-464d-b59a-bf4ebc5a0ca8. pdf [accessed 2019-06-24]

13. Erasmus V, Huis A, Oenema A, van Empelen P, Boog MC, van Beeck EHE, et al. The ACCOMPLISH study. A cluster randomised trial on the cost-effectiveness of a multicomponent intervention to improve hand hygiene compliance and reduce healthcare associated infections. BMC Public Health 2011 Sep 24;11:721 [FREE Full text] [doi: 10.1186/1471-2458-11-721] [Medline: 21943482]

14. Beeck E, Vos G, Beeck E, Boog M, Erasmus V, Polinder S, et al. Accomplish symposium. 2014 Apr 1. URL: https://www. accomplish-handhygiene.nl/download/ACCOMPLISHresultaten.pdf [accessed 2019-06-18]

15. Zomer TP, Erasmus V, Looman CW, Van Beeck EF, Tjon-A-Tsien A, Richardus JH, et al. Improving hand hygiene compliance in child daycare centres: a randomized controlled trial. Epidemiol Infect 2016 Sep;144(12):2552-2560 [FREE Full text] [doi: 10.1017/S0950268816000911] [Medline: 27193613]

16. Hand Hygiene in Outpatient and Home-based Care and Long-term Care Facilities: A Guide to the Application of the WHO Multimodal Hand Hygiene Improvement Strategy and the "My Five Moments for Hand Hygiene" Approach. Geneva: World Health Organization; 2012. URL: https://apps.who.int/iris/bitstream/handle/10665/78060/9789241503372_eng. pdf:jsessionid=5323786B5125752D161D8CA92B23D413?sequence=1 [accessed 2019-06-18]

17. Huis A, van Achterberg T, de Bruin M, Grol R, Schoonhoven L, Hulscher M. A systematic review of hand hygiene improvement strategies: a behavioural approach. Implement Sci 2012 Sep 14;7:92 [FREE Full text] [doi: 10.1186/1748-5908-7-92] [Medline: 22978722]

18. Pittet D, Hugonnet S, Harbarth S, Mourouga P, Sauvan V, Touveneau S, et al. Effectiveness of a hospital-wide programme to improve compliance with hand hygiene. The Lancet 2000 Oct 14;356(9238):1307-1312. [doi:

10.1016/s0140-6736(00)02814-2] [Medline: 11073019]

19. Helder OK, Brug J, Looman CWN, van Goudoever JB, Kornelisse RF. The impact of an education program on hand hygiene compliance and nosocomial infection incidence in an urban neonatal intensive care unit: an intervention study with before and after comparison. Int J Nurs Stud 2010 Oct;47(10):1245-1252. [doi: 10.1016/j.ijnurstu.2010.03.005] [Medline: 20381804]

20. Sax H, Uçkay I, Richet H, Allegranzi B, Pittet D. Determinants of good adherence to hand hygiene among healthcare workers who have extensive exposure to hand hygiene campaigns. Infect Control Hosp Epidemiol 2007

Nov;28(11):1267-1274. [doi: 10.1086/521663] [Medline: 17926278]

21. Pittet D. Improving adherence to hand hygiene practice: a multidisciplinary approach. Emerg Infect Dis 2001;7(2):234-240 [FREE Full text] [doi: 10.3201/eid0702.010217] [Medline: 11294714]

22. Bartholomew L, Parcel G, Kok G, Gottlieb N, Fernández M. Planning Health Promotion Programs: An Intervention Mapping Approach. 3rd edition ed. California: Jossey-Bass; 2011.

23. Handsome: handhygiëne in verpleeghuizen.: Zorg voor beter; 2019 May 03. URL: https://www.zorgvoorbeter.nl/handsome [accessed 2019-06-18]

24. Persoonlijke hygiëne: Verpleeghuizen, woonzorgcentra, voorzieningen voor kleinschalig wonen voor ouderen.: Werkgroep Infectie Preventie; 2014. URL: https://tinyurl.com/wpfqr8p [accessed 2019-06-18]

25. Hand Hygiene: Why, How \& When? Geneva: World Health Organization.: World Health Organization; 2009. URL: https:/ /www.who.int/gpsc/5may/Hand Hygiene Why How and When Brochure.pdf [accessed 2019-06-18]

26. WHO Guidelines on Hand Hygiene in Health Care. Geneva: World Health Organization; 2009. URL: https://apps.who.int/ iris/bitstream/handle/10665/44102/9789241597906 eng.pdf?sequence=1 [accessed 2019-06-18]

27. Wu K, Lee SS, Chen J, Chen Y, Tsai H, Chen Y, et al. Identifying heterogeneity in the Hawthorne effect on hand hygiene observation: a cohort study of overtly and covertly observed results. BMC Infect Dis 2018 Aug 06;18(1):369 [FREE Full text] [doi: 10.1186/s12879-018-3292-5] [Medline: $\underline{\text { 30081843] }}$

28. McGeer A, Campbell B, Emori TG, Hierholzer WJ, Jackson MM, Nicolle LE, et al. Definitions of infection for surveillance in long-term care facilities. American Journal of Infection Control 1991 Feb;19(1):1-7. [doi: 10.1016/0196-6553(91)90154-5] [Medline: 1902352]

29. Diaz MH, Silkaitis C, Malczynski M, Noskin GA, Warren JR, Zembower T. Contamination of examination gloves in patient rooms and implications for transmission of antimicrobial-resistant microorganisms. Infect Control Hosp Epidemiol 2008 Jan;29(1):63-65. [doi: 10.1086/524338] [Medline: 18171189]

30. Veiligheid en Kwaliteit: Project Handen uit de Mouwen.: Stichting Samenwerkende Rijnmond Ziekenhuizen URL: http:/ /www.stichting-srz.nl/veiligheid-en-kwaliteit/project-handen-uit-de-mouwen/project-handen-uit-de-mouwen/

31. Auditor training.: Hand Hygiene Australia URL: https://www.hha.org.au/audits/auditor-training [accessed 2019-05-03] 
32. Krikland K. A Qualitative Analysis of Facilitators and Barriers to Hand Hygiene Improvement at New Hampshire Hospitals during a Statewide Hand Hygiene Campaign. 2011 Nov. URL: https://www.healthynh.com/images/PDFfiles/high-5/ FINAL\%20REPORT\%20K\%20Kirkland\%20\%20HH\%20November\%202011.pdf [accessed 2020-02-19]

33. MetroHealth Cuts Harm with 'Wash-In, Wash-Out'.: America's Essential Hospitals; 2013 Jan 09. URL: https://tinyurl.com/ suh3ypm [accessed 2020-02-18]

34. Sunkesula VCK, Meranda D, Kundrapu S, Zabarsky TF, McKee M, Macinga DR, et al. Comparison of hand hygiene monitoring using the 5 Moments for Hand Hygiene method versus a wash in-wash out method. Am J Infect Control 2015 Jan;43(1):16-19. [doi: 10.1016/j.ajic.2014.10.003] [Medline: 25564119]

35. Surveillance Netwerk Infectieziekten in Verpleeghuizen: Resultaten van wekelijkse surveillance, Referentiecijfers 2011 2015.: Rijksinstituut voor Gezondheid en Milieu URL: https://www.rivm.nl/sites/default/files/2018-11/ Referentiecijfers\%20Incidentie\%20SNIV\%202011-2015 def.pdf [accessed 2019-06-18]
Abbreviations
HAI: health care-associated infection.
HH: hand hygiene.
HHC: hand hygiene compliance.
WHO: World Health Organization.

\author{
Edited by G Eysenbach; submitted 11.12.19; peer-reviewed by C Smith, D Szinay; comments to author 13.02.20; revised version \\ received 20.02.20; accepted 26.02.20; published 01.05.20 \\ Please cite as: \\ Teesing GR, Erasmus V, Petrignani M, Koopmans MPG, de Graaf M, Vos MC, Klaassen CHW, Verduijn-Leenman A, Schols JMGA, \\ Richardus JH, Voeten HACM \\ Improving Hand Hygiene Compliance in Nursing Homes: Protocol for a Cluster Randomized Controlled Trial (HANDSOME Study) \\ JMIR Res Protoc 2020;9(5):e17419 \\ URL: https://www.researchprotocols.org/2020/5/e17419 \\ doi: $\underline{10.2196 / 17419}$ \\ PMID: 32356772
}

(C) Gwen R Teesing, Vicki Erasmus, Mariska Petrignani, Marion P G Koopmans, Miranda de Graaf, Margreet C Vos, Corné H W Klaassen, Annette Verduijn-Leenman, Jos M G A Schols, Jan Hendrik Richardus, Helene A C M Voeten. Originally published in JMIR Research Protocols (http://www.researchprotocols.org), 01.05.2020. This is an open-access article distributed under the terms of the Creative Commons Attribution License (https://creativecommons.org/licenses/by/4.0/), which permits unrestricted use, distribution, and reproduction in any medium, provided the original work, first published in JMIR Research Protocols, is properly cited. The complete bibliographic information, a link to the original publication on http://www.researchprotocols.org, as well as this copyright and license information must be included. 